\title{
The Effects of Active Games on Aggressive Behaviors of 7-Year-Old Children
}

\author{
Mehmet inAN $^{* a}$, Cengiz KARAGÖZOĞLU ${ }^{b}$, Özgür ŞiMŞEK ${ }^{c}$ \\ ${ }^{a}$ Marmara University, Ataturk Faculty of Education, Istanbul/Turkey \\ ${ }^{\mathrm{b}}$ Marmara University, School of Physical Ed. and Sports, Istanbul/Turkey \\ ${ }^{c}$ Ministry of National Education, Istanbul/Turkey
}

\section{Article Info}

DOI: $10.14527 /$ pegegog.2014.003

Article history:

Received 11 April 2013

Revised 14 October 2013

Accepted 19 January 2014

Keywords:

Children's educational play,

Aggressive behaviour,

Goodenough human drawing test.

\section{Abstract}

This research is conducted to determine the possible effects of aggressive behaviours of 7 -year- old children during active games. The video tapes from various angles of children while playing games are used as the main assessment tool for collecting the data as well as "The Goodenough-Harris Drawing Test" and "The Observation Form for Aggressive Behaviours of Children during the Games". The observation form is used to record the active and passive aggressive behaviours of the child towards his/her teammates, the opponent team players, the referee/s and the game instruments and facilities. This form is designed by the researchers and refined by views of the experts.

\section{Introduction}

Playing games is essentially a concept which we associate with children. It calls to mind a number of toys, movement, fighting and fantasy games and role modelling (McCusker \& Van Doren, 2007). Although the main aim of the play is having fun and positive reasons, there are many studies which focused on appearance of negative behaviours during playing. In different game settings, mostly computer games, sport related games, rough and tumble play of father and son (Tannock, 2011) and similar ones frequently attaching with aggressiveness and related behaviour (Flanders, Simard, Paquette, Parent, Vitaro, Pihl, \& Seguin, 2010). Additionally it's reported in some studies, aggressive behaviour is frequently observed in schools across Turkey (Dilekmen, Ada \& Alver, 2011).

There are numerous definitions related with aggressiveness in the literature. Baumann (1994) described aggressiveness as a personality characteristic of showing an internal aptitude through aggressive behaviour. The most widely met descriptions of aggressiveness have a common property that can be stated as "harming someone or something" (ikizler \& Karagözoğlu, 1997; Şahin, 2003; Tiryaki, 2000).

People show intentional or involuntary behaviour where the environment they live in. Some of these behaviours can be disturbing for others. Such as pushing an object, pulling, throwing, breaking or directing the object to a person, or indirectly verbal or physical attack to someone. A few people may feel comfortable with these behaviours, but disturbing other people or harming some objects are

* Corresponding author: minan@marmara.edu.tr 
perceived as aggressiveness. In some cases, aggressiveness shows itself as an act of self-protection or a way of coping with a problem like legitimately attacking to an opponent in a sportive activity.

Sport is described as a set of ruled holistic, physical, mental and spiritual activities which are performed within particular rules and enable oneself to win or achieve something to satisfy his/her inner desires (Şahin, 2002). During a sport activity, whether it is an athlete or spectator may be observed acting out of rule physically or verbally. Some of the actors who have control of their drives can manage others' uncontrolled behaviours as well as themselves'. Beginning from the childhood, behaviours appears mostly in game forms (İnan, 2003; Inan, 2005; Oktay, 1999; Onay, 2007; Önder, 1999; Pehlivan, 2005; Sevinç, 2004). Huizinga (1949) describes playing games as "older than culture" and perceives games as an important instrument which could be the start of different cultural forms. And (2003) describes playing games as "catharsis, getting rid of the energy surplus, physiological drive and satisfying the imitation instinct".

From the human drawing test perspective, seven years' old children are in the "schematic" developmental phase. In this age, drawings start to differentiate from the "line-man" into the real person view (Skybo \& Ryan-wenger, 2007). Writing and drawing provide opportunities for us to identify, explain, compare, persuade and question (Mavers, 2011).

\section{Method}

\section{Research Design}

This study is a field research based on observations. The aggressive behaviours of children tried to be retrieved through observational tools.

\section{Participants}

Study conducted with 13 seven years old children (girls=4, boys=9) in a primary school, in Istanbul. Prior to the study, all legal permissions were taken from parents and school administration. The only criterion was that participating children would be volunteers to take parts in the games.

\section{Instrument}

Two educational and sportive games were organized in the gymnasium for the sample group of the study. With help of the cameras where positioned to see the game area from two different angles, children's play was recorded synchronized with the games. The behaviours of the children were recorded to the video before, during and after the games. The video tapes are then watched and analyzed by the researchers and the findings were recorded on the observation form.

Before the games, children were asked to wait in a designated area without any comment or direction for five minutes and recorded to camera. After that, children were taken to the game area and were directed to play an educational game and a stafet race. After the activity, like the beginning, children were asked to wait in the designated area. All the activity and waiting periods consecutively recorded to camera.

\section{Goodenough-Harris Drawing Test:}

One of the widely known drawing test used for drawing test instrument. Test is used for examining the behavioural problems, personality and analysing emotional background of children 4 to 14 year olds. Goodenough test originally developed in 1926. Turkish validation realized in 1972 by Ucman. There are 27 criteria for scoring the test including the openly drawing or not drawing of the genital area, omitting drawing the central part of the figure, clothing the drawn person, adding fruit trees, extremely small drawing, bad connection of the body parts, cutting hands, omitting to draw the arms or legs, adding or 
highlighting the belly, drawing sharp teeth, big hands, transparent figure, athwart figure, highlighting the genital area, drawing the legs attached and similar ones.

\section{The Observation Form for Aggressive Behaviours of Children During the Games:}

A matrix-shaped observation form designed for scoring the actual aggressive behaviour for each child from the camera recordings. The Observation Form for Aggressive Behaviours of Children during the Games was filled out prior to the game, during the game and after the game setting for any aggressive behaviour. Researcher's marked each observed behaviour for each child separately.

Application of the Goodenough-Harris Drawing Test was conducted in a classroom setting via providing a blank a4 paper and pencil to the children, without any time restriction and following with the original test procedure. Children were asked to draw a free human figure with their own creativity; they were free for drawing any desired person. When scoring the test, any criteria mentioned above scored as $0.5,1.0,2.0$ or 3.0 and non-presence of the criterion means no score as well.

\section{Data Analysis}

Scored game observation forms, personal information about children and the Goodenough-Harris Test scores entered into statistical software. Non-parametrical statistics Wilcoxon Signed Ranks Test and Mann Whitney $U$ tests were used to analyse data, according to the small sample size. Evaluation of the observed aggressive behaviour rates scored as if all 13 children shows the behaviour, rated as $13 / 13=1$, for converting the number related with sample, similar to percentages.

\section{Results}

Prior to the educational game; pushing, pulling, blocking, hitting behaviours and physical aggression were observed among students. Although there were similarities in the behaviours of the students after the game; a significant decrease was observed in passing and blocking behaviours.

Verbal aggression behaviours such as "yelling out loud" and "verbal aggression" were observed more than other behaviours before and after the educational game. While behaviours like "insulting" and "self-yelling out loud" were not observed before the educational game, "self-yelling out loud" after the game was significantly increased.

Aggressive behaviours toward the game materials like "tossing on the floor, throwing and kicking" before the educational game were more prevalent, "consciously stepping on materials" behaviour follow it and "breaking the material" behaviour was displayed the least while "breaking the material" and "kicking the material" behaviours were more prevalent. "Deliberately stepping on the game materials" was displayed as less frequent after the game.

During shuttle games, aggressive behaviours observed as mostly "pulling" and "hitting", also "pushing" behaviour was one of the most observed one. "Biting" and "chopping" were not observed. This result is a significant observation, because stafet games are very competitive.

Goodenough -Harris drawing test scores which expected to be associated with aggression showed no significant difference among children. In order to see the differences with respect to gender, the MannWhitney $U$ test was run on the drawing test scores and aggression scores of gender groups during the active games and stafet games. No significant difference was found between the gender groups.

Children were divided into two groups according to their "total drawing test scores", one group consisted with children who scored low (2.0) points and the other group consisted of children who scored high (3.0) points. Each group's total aggression points which were obtained by the group 
members during and after the educational games and stafet races then compared. The aggression scores observed during and after educational games and stafet races did not show a significant difference in terms of Goodenough -Harris drawing test scores.

\section{Discussion, Conclusion \& Implementation}

Aggressive behaviours mostly observed prior to the game and after the game on the dynamic educational games setting. On the contrary, children displayed aggressive behaviours mostly during the game and directed to the teammates in stafet games. This result is parallel with Tannock's (2011) findings on 5 years old children.

Blocking behaviours which related with physical aggressiveness observed significantly low after the game compared with before the game. This result shows expectation of the competition can be a triggering factor for the children during stafet games.

Yelling out loud and self-yelling behaviours were significantly higher at the end of the game, comparing to prior to the game period. This result shows that game itself can be an aggressive behaviour creating experience. Similarly, aggressive behaviour directed to game materials was significantly high at the end of the game then before the game. Similarly Nelson, Gelfand and Hartmann (1969) explain this phenomenon as "competition-induced frustration enhances both imitative and total aggression for children, especially for boys". This shows a parallel result with our study. Also in our study boys were significantly more aggressive to game materials after the game. They showed "kicking", "stepping" and "tearing off" behaviours more than girls. This result is parallel with Tannock (2011) and Dağ|ıŏlu, Deniz and Kaan's findings.

In this study no significant relationship has been found between Goodenough -Harris drawing test scores and children's aggressive game behaviour. Also there were no significant difference between boys and girls respected to Goodenough - Harris drawing test scores. Dağlığlu, Deniz \& Kaan's study has similar results about lack of the significant difference between gender "anger-on aggressiveness" revealed that 5-year-old sample. 
Pegem Journal of Education \& Instruction, 4(1), 2014, 47-58

Pegem Eğitim ve Öğretim Dergisi, 4(1), 2014, 47-58

www.pegegog.net

\title{
7 Yaş Çocuklarında Hareketli Oyunların Saldırganlık Davranışları Üzerine
}

\section{Etkileri}

\author{
Mehmet inAN $^{a^{*}}$, Cengiz KARAGÖZOĞLU ${ }^{b}$, Özgür ŞiMŞEK ${ }^{c}$ \\ ${ }^{a}$ Marmara Üniversitesi, Atatürk Eğitim Fakültesi, İstanbul/Türkiye \\ ${ }^{b}$ Marmara Üniversitesi, Beden Eğt.ve Spor Yüksekokulu, İstanbul/Türkiye \\ ${ }^{c}$ Milli Eğitim Bakanlığı, İstanbul/Türkiye
}

\section{Makale Bilgisi}

DOI: $10.14527 /$ pegegog.2014.003

Makale geçmişi:

Geliş $\quad 11$ Nisan 2013

Düzeltme 14 Ekim 2013

Kabul 19 Ocak 2014

Anahtar kelimeler:

Eğitici oyun

Saldırganlık

Goodenough Bir İnsan Çiz Testi.

\section{Öz}

Bu araştırma, yedi yaşındaki çocukların hareketli oyunlar esnasındaki saldırganlık davranışlarını belirlemeye yönelik olarak yapılmışır. Araştırmada veri toplama aracı olarak "Goodenough-Harris İnsan Çizim Testi" ve "Çocuklarda Oyun Ortamında Saldırgan Davranışları Gözlem Formu" kullanıııışır. Çocukların gerçek oyun ortamında çeşitli açılardan çekilen video görüntüleri asıl veri toplama aracını oluşturmaktadır. Gözlem formu, çocuğun kendi arkadaşlarına, rakip takıma, hakemlere ve oyun araçlarına yönelik olarak gösterdiği aktif ve pasif saldırganlık davranışlarını izlemeye yöneliktir. Gözlem formu, uygulayıcılar tarafından tasarlanmış ve alan uzmanlarının görüşleri alınarak düzenlenmiştir. Eğitsel oyun öncesi ve sonrası sözel saldırganlık davranışlarından "yüksek sesle bağırma" ve "sözlü tacizde bulunmanın" daha çok yapıldığı görülmektedir. Hakaret içeren ifadeler ile kendi kendine bağırma davranışları eğitsel oyun öncesi görülmemiştir. Yüksek sesle bağırma ve kendi kendine bağırma davranışı oyun sonrasında anlamlı ölçüde artış göstermiştir. Stafet yarışı esnasında takım arkadaşlarına "yüksek sesle bağırma" ve "kendi kendine bağırma" sözlü saldırganlık davranışları en yüksek yüzdeye sahiptir. Goodenough-Harris çizim testi skorları açısından yapılan değerlendirmede saldırganlıkla ilişkilendirilebilecek olan kriterler açııından kızlarda ve erkeklerde anlamlı farklılık görülmemiştir. Gruplar açısından farklııkları görmek için yapılan Mann Whitney $U$ istatistik analizlerinde cinsiyete göre çizim testi sonuçları ile hareketli oyunlar ve stafet oyunları esnasında gözlemlenen saldırganlık gözlem puanları arasında anlamlı farklıık bulunamamıştır. Toplam çizim testi puanı açısından çocuklar düşük (2.0) ve yüksek (3.0) puan alan iki gruba bölünerek eğitsel oyun ve stafet yarışları öncesinde, oyunlar sırasında ve sonrasında elde edilen saldırganlık puanları ve toplam saldırganlık puanları açısından farklılık araştııımıştır. İnsan çizim testlerinde alınan skorlar açııından eğitsel oyun ve stafet yarışlarında gözlemlenen saldırganlık puanları arasında anlamlı bir farklılığa rastlanmamıştır.

\section{Giriş}

Oyun, doğal olarak çocuklarla birlikte düşünülen bir kavramdır. Oyun denince akla sayısız oyuncak, hareket, mücadele ve fantezi oyunları ve rol modelleme gelmektedir (McCusker ve Van Doren, 2007). Oyun oynamanın amacı her ne kadar eğlence ve olumlu gerekçeler de olsa, oyun ortamlarında olumsuz davranışların ortaya çıkması ile ilgili çok sayıda araştırma bulunmaktadır. Bu oyun düzlemleri içerisinde özellikle bilgisayar oyunları, spor amaçlı oyunlar, baba ve çocuğun oynadığına benzer itiş-kakış ve yuvarlanma içeren oyunlar (Tannock, 2011) ve benzerleri sıklıkla şiddetle ve saldırgan davranışlarla ilişkilendirilmektedir (Flanders, Simard, Paquette, Parent, Vitaro, Pihl, ve Seguin, 2010). Ayrıca bazı çalışmalarda özellikle Türkiye'de okul ortamlarında saldırgan davranışların yoğun olarak gözlendiği rapor edilmektedir (Dilekmen, Ada ve Alver, 2011).

*Yazar: minan@marmara.edu.tr 
Saldırganlıkla ilgili olarak alan yazında pek çok ifadeler vardır. Baumann (1994), saldırganlığı, saldırgan eylemde bulunmaya yönelik içsel bir yatkınlığı gösteren bir kişilik özelliği olarak tanımlar. Bir kişi veya nesnenin zarar görmesi (íkizler ve Karagözoğlu, 1997; Şahin, 2003; Tiryaki, 2000), saldırganlıkla ilgili yapılan tanımlamalarda en çok karşımıza çıkan ortak nokta olarak görülebilir.

Insanlar yaşadıkları çevrelerde bilinçli veya istemsiz davranışlarda bulunurlar. Bu davranışların bir kısmı rahatsız edici olabilmektedir. Örneğin, bir nesneyi itmek, çekmek, fırlatmak, kırmak, ya da bu nesneleri bir canlıya doğru yönlendirmek, veya bir canlıya dolaylı, sözlü ve fiziksel davranışlarda bulunmak gibi. Tüm bu davranışların bazıları tarafından "rahatsız edici" bulunmaması, genelde bir "sorun" teşkil etmez. Ancak, davranışların ikincil kişileri rahatsız etmeye başlaması ya da nesnelerin zarar görmeye başlaması "saldırganlık" ile ilgili düşünceleri akla getirmeye başlar. Bazen saldırmak, kendini korumak biçiminde de karşımıza çıkabilmektedir. Kimi zaman da bir işin üstesinden gelmek için başvurulan bir yol olabilmektedir. Örneğin, spor aktivitelerinde rakibe kurallar çerçevesinde hamle yapmak gibi.

Spor, "yenme ve muktedir olma gibi, insanın bilinçaltı arzularının tatminini amaç edinen, belirli kurallar içerisinde yapılan, rekabete dayalı sosyalleştirici, bütünleştirici, fiziki, zihni ve ruhi faaliyetlerin bütünü" (Şahin, 2002) şeklinde tanımlanır. Sporla ilgili yaşantılara bakıldığında, gerek sporu yapan ya da seyirci konumunda kalan kişilerin sözel ve fiziksel olarak canlılara veya eşyalara karşı kural dışı hareketlerde bulunulduğu hemen hemen her dönemde görülmektedir. Saldırganlığın çok net olarak görüldüğü bu ortamlarda, bu itkilerini kontrol edebilenler, kendini yönettikleri gibi çevresindekilerinin kontrol dışı hareketlerine de zaman zaman engel olabilmektedirler. Çocukluk döneminden itibaren yaşamdaki davranışlar daha çok oyun formuyla (İnan, 2003; İnan, 2005; Oktay, 1999; Onay, 2007; Önder, 1999; Pehlivan, 2005; Sevinç, 2004) karşımıza çıkmaktadır. Huizinga (1949) oyunu "kültürden daha eski" bir kavram olarak ifade eder ve oyunu, "çeşitli kültür biçimlerinin doğuşuna kaynaklık eden" önemli bir araç olarak görür. And (2003) ise oyunu; "boşalma, enerji fazlasını atma, fizyolojik itki, taklit içgüdüsünün doygunluğunu sağlamak" şeklinde ifade eder.

Çizim testleri değerlendirmesi açısından yedi yaşındaki çocuklar "şematik dönem" olarak adlandırılan gelişim evresinde bulunmaktadır. Bu yaştaki çocuklarda çizimler çizgi-adam formundan çıkarak gerçek insan görünümüne kavuşmaya başlamaktadır (Skybo ve Ryan-wenger, 2007). Yazma ve çizim bize tanımlama, açıklama, kıyaslama, ikna ve sorgulama için fırsatlar sağlar (Mavers, 2011).

\section{Yöntem}

\section{Araştırma Modeli}

Araştırma gözleme dayalı saha araştırması niteliğindedir. Gözlem araçları yoluyla çocukların saldırganlık davranışları belirlenmeye çalışılmıştır.

\section{Katılımcılar}

Araştırma, İstanbul'da özel bir ilköğretim okulunda okuyan 7 yaşındaki 13 çocukla (kız=4, erkek=9) birlikte yapılmıştır. Araştırma için okul idaresi ile görüşülmüş, veliler haberdar edilmiş ve okul idaresinin çalışmayı yapabileceğimize dair onayı alındıktan sonra çalışma yapıımıştır. Oyunlara katılım açısından çocukların istekli olması prensibi aranmıştır.

\section{Veri Toplama Aracı}

Çocuklara eğitsel ve stafet tarzında iki çeşit hareketli oyun oynatılmıştır. Eğitsel oyunlar, daha çok kişilik, sosyal ve duygusal gelişime katkılarını psikomotor davranışlar aracılığı ile sağlar. Stafet yarışları (mekik koşuları), motorik özellikleri geliştirmeye yarayan oyunlardır (İnan, 2003). Oyunlar, bizzat 
araştırmacılar tarafından hazırlanmış ve oynatılmıştır. Oyun esnasında iki farklı açıdan eş zamanlı video kayıtları yapılmıştır.

\section{Çocuklarda oyun ortamında saldırgan davranışları gözlem formu:}

Çocukların oyun öncesi, oyun esnasındaki ve oyun sonrasındaki muhtemel gösterebilecekleri belirlenen 23 farklı saldırganlık davranışının izlenebilmesi için önceden geliştirilmiş ve araştırmacılarla birlikte rehberlik uzmanı ve sınıf öğretmeni olan altı alan uzmanı tarafından görünüş geçerliği sınanmıştır. Gözlem formu matris şeklinde tasarlanmış olup, değerlendirme yapan uzmanlar görüntüleri izlerken çocukların oyun öncesi, oyun esnasındaki ve oyun sonrasındaki saldırganlık kriterlerine uygun davranışlarını kendi arkadaşlarına, rakip takıma ve oyun araçlarına yönelik olarak değerlendirmişlerdir.

\section{Goodenough-Harris Çizim Testi:}

İlk olarak Goodenough tarafından 1926 yılında geliştirilmiştir. Projektif testler içerisinde özellikle 4-14 yaş gruplarında davranış bozuklukları da dahil olmak üzere kişilik ve duygusal yapının ortaya çıkarılması için yaygın olarak kullanılmakta olan bir testtir. Testin Türk örneklemine uyarlanması Uçman tarafından 1972 yılında yapılmıştır. Testin puanlamasında 27 farklı kriter bulunmaktadır. Bu kriterler genital bölgelerin açıkça çizilmiş olması, genital bölgelerin gizlenmesi, genital bölgelerin çizilmemesi, figürün merkez parçasının çizilmemesi, çizilen insanı giydirme, çizime meyve ağaçları eklenmesi, çizimin ufak olması, vücut kısımlarının zayıf birleştirilmesi, ellerin kesilmiş olması, çizimdeki kolların ve bacakların çizilmemesi, göbek deliğinin eklenmesi veya vurgulanmış olması, sivri dişler çizilmesi, büyük eller olması, figürün şeffaf olması, figürün yana yatmış olması, genital bölgelerin vurgulanması, bacakların birbirine yapışık çizilmesi ve benzeri kriterlerdir. Test uygulaması sınıf ortamında araştırmacılar tarafından çocuklara birer tane boş dosya kağıdı ve kurşun kalem verilerek, süre sınırı konulmadan, orijinal test kurallarına bağlı kalınarak yapılmıştır. Çocuklardan kağıda bir insan figürü çizmesini istemiştir. Herhangi bir zaman kısıtlaması olmadığı ve çizimin tamamen çocuğun yaratıcılığına bırakıldığı araştırmacı tarafından her belirtilmiştir. Puanlama için belirtilen kriterlerin çizimde yer alması durumda 0.5, 1.0, 2.0 ve 3.0 puan şeklinde notlandırılma yapılmış, çizimin içinde kriterlerin yokluğunda ise puan verilmemiştir.

\section{Verilerin Toplanması}

Oyun esnasındaki verilerin toplanması amacıyla öncelikle iki farklı açıya yerleştirilen kameralar yardımıyla oyun yaşantıları eş zamanlı olarak kaydedilmiştir. Daha sonra değerlendirme işlemi ile birlikte uzmanlar tarafından Çocuklarda Oyun Ortamında Saldırgan Davranışları Gözlem Formu yoluyla daha önceden tanımlanmış olan davranışlar işaretlenerek belirtilmiştir. Gözlem formlarındaki veriler bilgisayar ortamına alınarak değerlendirilmiştir.

Uygulamanın başlangıcında herhangi bir müdahale olmaksızın çocuklardan beş dakika süreyle sınırlandırılmış bir alanda beklenmeleri istenilmiş ve davranışları kamerayla kaydedilmiştir. Ardından önceden planlanmış olan bir eğitsel oyun ve bir de stafet yarışı yapılmıştır. Etkinlik sonunda tıpkı başlangıçta olduğu gibi bekleme süresi verilerek, oyun sonu davranışları kaydedilmiştir.

Goodenough-Harris Çizim Testi ise çocuklara sınıf ortamında uygulanmış ve ardından, daha önceden hazırlanmış bulunan veri tabanı programından yararlanılarak 27 farklı durum ve ayrıca kalemin bastırılması, gölgelendirilmiş çizim, büyük resim çizme ve toplam puan da ayrıca değerlendirilerek hesaplanmıştır.

\section{Verilerin Analizi}

Çocuklarda Oyun Ortamında Saldırgan Davranışları Gözlem Formu video kayıtlarından beş uzman (okul rehberlik uzmanı, sınıf öğretmeni ve üç araştırmacı) tarafından izlenerek formlara işaretleme yapılmıştır. Veriler bilgisayar ortamında bir araya getirilerek, Çocuklarda Oyun Ortamında Saldırgan Davranışları Gözlem Formu için 414 alt değişken, Goodenough-Harris Çizim Testi için ise 27 değişkenden 
oluşan bir veri tabanı oluşturulmuştur. Bunun ardından saldırganlık için fiziksel saldırganlık, sözel saldırganlık, talimatlara uymama ve oyun araç-gereçlerine yönelik saldırganlık puanları hesaplanmıştır.

Verilerin analizinde örneklemin küçük örneklem olması da dikkate alınarak olgusal değerlendirme yaklaşımları ve Non parametrik istatistiklerden Wilcoxon Signed Rank Test ve Mann Whitney U testleri uygulanmıştır. Değerlendirmede davranışların gözlenme oranları 13 çocuğun tamamı davranışı gösteriyorsa 13/13=1 şeklinde hesaplanarak, yüzdelik şeklinde anlaşılabilecek şekilde tablolarda verilmiştir.

\section{Bulgular}

Çocukların eğitsel oyun oynamadan önceki fiziksel saldırganlıkları görülmektedir. Buna göre, eğitsel oyun öncesinde en çok görülen fiziksel davranış gösterme sıklığı itme ve çekme davranışlarıdır (Tablo 1). Sonra sırasıyla "önüne geçme, engelleme" ve "vurma" davranışları gelmektedir. Bu tabloya göre eğitsel oyun öncesinde en az görülen fiziksel saldırganlık davranışlarının "çelmeleme" ve "herhangi bir şekilde canını yakma" olduğu görülmektedir. Çocuklarla oynanan eğitsel oyun sonrasında davranışlar benzerlik göstermekle birlikte, önüne geçme, engelleme davranışında anlamlı bir düşme gözlenmiştir ( $p<.05)$.

Tablo 1.

Eğitsel Oyun Öncesinde ve Sonrasında Kendi Arkadaşlarına Yönelik Fiziksel Saldırganlık Gösterme Oranları Karşılaştırması.

\begin{tabular}{lcccrr}
\hline Davranış & N & $\begin{array}{c}\text { Önce } \\
\text { Ort. }\end{array}$ & $\begin{array}{c}\text { Sonra } \\
\text { Ort. }\end{array}$ & $\mathbf{Z}$ & $\mathbf{p}<$. \\
\hline Önüne geçme, engelleme & & Ort. & .046 \\
İtme & 13 & .6923 & .3846 & -2.000 & .046 \\
Çekme & 13 & .8462 & .8462 & .000 & 1.000 \\
Vurma & 13 & .8462 & .8462 & .000 & 1.000 \\
Isırma & 13 & .6154 & .8462 & -1.732 & .083 \\
Çimdikleme & 13 & .3846 & .2308 & -1.414 & .157 \\
Çelmeleme & 13 & .3846 & .2308 & -1.414 & .157 \\
Diğer herhangi bir şekilde canını yakma & 13 & .3077 & .4615 & -1.000 & .317 \\
\hline
\end{tabular}

Tablo 2'ye göre, stafet türü oynanan oyunlarda çocukların fiziksel saldırganlık gösterme oranları en çok "çekme" ve "vurma" davranışlarındadır. "Itme" davranışı en çok görülen fiziksel saldırganlıklar arasındadır. Hiç görülmeyen fiziksel saldırganlık davranışları ise "ısırma" ve "çimdikleme" dir. Takım rekabetinin olduğu stafet tarzı oyunlarda fiziksel saldırganlık davranışlarından ısırma, çimdikleme gibi davranışların kendi takım arkadaşlarına karşı hiç yapılmamış olması dikkat çekicidir.

Tablo 2.

Stafet Oyunu Esnasında Kendi Arkadaşlarına Fiziksel Saldırganlık Gösterme Oranları.

\begin{tabular}{lrrr}
\hline Stafet Oyunu Esnasında & Toplam & $\mathbf{N}$ & Ort. \\
\hline Önüne geçme, engelleme & 3.00 & 13 & .2308 \\
İtme & 6.00 & 13 & .4615 \\
Çekme & 7.00 & 13 & .5385 \\
Vurma & 7.00 & 13 & .5385 \\
Isırma & .00 & 13 & .0000 \\
Çimdikleme & .00 & 13 & .0000 \\
Çelmeleme & 1.00 & 13 & .0769 \\
Diğer herhangi bir şekilde canını yakma & 3.00 & 13 & .2308 \\
\hline
\end{tabular}


Eğitsel oyun öncesi ve sonrası sözel saldırganlık davranışlarından "yüksek sesle bağırma" ve "sözlü tacizde bulunmanın" daha çok yapıldığı Tablo 3' te görülmektedir. Hakaret içeren ifadeler ile kendi kendine bağırma davranışları eğitsel oyun öncesi görülmemiştir. Yüksek sesle bağırma ve kendi kendine bağırma davranışı oyun sonrasında anlamlı ölçüde artış göstermiştir ( $p<.01)$.

Tablo 3.

Eğitsel Oyun Öncesi ve Sonrasında Kendi Arkadaşlarına Sözlü Saldırganlık Davranışları Gösterme Oranları Karşılaştırması.

\begin{tabular}{lccccrr}
\hline Eğitsel Oyun Öncesi-Sonrası & Toplam & $\mathbf{N}$ & $\begin{array}{c}\text { Önce } \\
\text { Ort. }\end{array}$ & $\begin{array}{c}\text { Sonra } \\
\text { Ort. }\end{array}$ & $\mathbf{Z}$ & $\begin{array}{r}\mathbf{p}<. \\
\text { Yüksek sesle bağırma }\end{array}$ \\
Hakaret içeren ifadeler & 1.00 & 13 & .0769 & .7692 & -3.000 & .003 \\
Kendi kendine bağırma & .00 & 13 & .0000 & .0769 & -1.000 & .317 \\
Sözlü tacizde bulunma & .00 & 13 & .0000 & .8462 & -3.317 & .001 \\
\hline
\end{tabular}

Stafet yarışları öncesinde ve sonrasında saldırganlık davranışları gözlenmemiş olup sadece oyun esnasında gözlenen davranış oranları takım arkadaşlarına "yüksek sesle bağırma" (8.0) ve "kendi kendine bağırma" (7.0) sözlü saldırganlık davranışları en yüksek yüzdeye sahiptir.

Hem eğitsel, hem de stafet tarzı oyun esnasında öğretmene yönelik pasif saldırganlık davranışları tespit edilmiştir. Buna göre, kurallara uymama davranışı çocuklarda oyun esnasında daha az görülürken (ortalama .31), "talimatlara pasif karşı gelme" daha yüksek bir oranda görülmüştür (.46).

Tablo 4.

Eğitsel Oyun Öncesi ve Sonrasında Oyun Malzemelerine Yönelik Saldırganlık Davranışları Oranı.

\begin{tabular}{lcccrc}
\hline Eğitsel Oyun Öncesi ve Sonrası & $\mathbf{N}$ & $\begin{array}{c}\text { Önce } \\
\text { Ort. }\end{array}$ & $\begin{array}{c}\text { Sonra } \\
\text { Ort. }\end{array}$ & $\mathbf{Z}$ & $\mathbf{p}<$. \\
\hline Malzemeleri yere atma ya da fırlatma & 13 & .6923 & .3846 & -1.414 & .157 \\
Oyun malzemelerinden parça koparma & 13 & .1538 & .5385 & -2.236 & .025 \\
Bilinçli olarak üstlerine basma & 13 & .6154 & .4615 & -.816 & .414 \\
Tekmeleme & 13 & .6923 & .5385 & -1.000 & .317 \\
\hline
\end{tabular}

Tablo 4'te, eğitsel oyun öncesinde oyun malzemelerine yönelik "yere atma, fırlatma, tekmeleme" davranışları daha sık görülürken, bunu "bilinçli olarak üstlerine basma" takip etmekte ve en az olarak "malzemelerden parça koparma davranışları" gelmektedir. Oyun sonrasında ise, "oyun malzemelerinden parça koparma" ile "tekmeleme" davranışları daha sık görülürken "bilinçli olarak oyun malzemelerinin üzerine basma" daha az görülmektedir. Eğitsel oyun sonrasında oyun malzemelerine yönelik şiddet davranışının daha çok arttığı söylenebilir.

Goodenough-Harris çizim testi skorları açısından yapılan değerlendirmede (Tablo 5), 27 kriterin varlığı ve büyük resim çizme açısından çocukların 2.69 puan ortalama değerlerinin bulunduğu görülmüştür. Kalemi bastırarak çizme 2.08; gölgelendirilmiş çizim ise .08 gibi düşük bir ortalama değer almıştır. Saldırganlıkla ilişkilendirilebilecek olan kriterler açısından kızlarda ve erkeklerde anlamlı farklılık görülmemiştir. Genital bölgenin çizilmesi puanlamada 3.0 ortalama ile göze çarpmaktadır ve her iki cinsiyette de aynı skor görülmüştür. Çizilen kişinin giydirilmesi puanı kızlarda (1.80) erkeklere göre (1.13) kısmen daha yüksek değerlendirilmiştir. Bu sonuç, saldırganlıkla bağlantılı bir sonuç olarak değerlendirilmemektedir ve Coşkun (2009) benzer bir sonuç bulmuştur. Gruplar açısından farklılıkları görmek için yapılan Mann Whitney $U$ istatistik analizlerinde Cinsiyete göre çizim testi sonuçları ile hareketli oyunlar ve stafet yarışları esnasında gözlemlenen saldırganlık gözlem puanları arasında anlamlı farklılık bulunamamıştır. Toplam çizim testi puanı açısından çocuklar düşük (2.0) ve yüksek (3.0) puan alan iki gruba bölünerek eğitsel oyun ve stafet yarışları öncesinde, oyunlar sırasında ve sonrasında elde 
edilen saldırganlık puanları ve toplam saldırganlık puanları açısından farkılık araştırılmışır. İnsan çizim testlerinde alınan skorlar açısından eğitsel oyun ve stafet yarışlarında gözlemlenen saldırganlık puanları arasında anlamlı bir farkıılığa rastlanmamıştır.

Tablo 5.

Goodenough-Harris Çizim Testi Toplam Skorlarına Göre Eğitsel Oyun ile Stafet Yarışları Toplam Puanları.

\begin{tabular}{lcccccc}
\hline \multirow{2}{*}{ Insan Çizim Testi Puanı } & \multicolumn{2}{c}{$\begin{array}{c}\text { Toplam Sözlü } \\
\text { Saldırganlık Puanı }\end{array}$} & \multicolumn{2}{c}{$\begin{array}{c}\text { Toplam Fiziksel } \\
\text { Saldırganlık Puanı }\end{array}$} & \multicolumn{2}{c}{ Toplam } \\
& Ortalamaldırganlık Puanı & S.Sapma & Ortalama & S.Sapma & Ortalama & S.Sapma \\
\cline { 2 - 7 } Alt & 1 & 1 & 14.25 & 9.9457 & 18.25 & 12.5 \\
Üst & 1.027 & 0.6305 & 14.778 & 6.2205 & 18.8889 & 8.2689 \\
Toplam & 1.019 & 0.7178 & 14.612 & 7.1126 & 18.6923 & 9.2049 \\
\hline
\end{tabular}

\section{Sonuç, Tartışma ve Öneriler}

Hareketli eğitici oyunlar sırasında çocukların saldırgan davranışları en çok oyun öncesi ve oyun sonrasında, stafet (mekik koşusu) içeren oyunlarda ise oyun sırasında ve takım arkadaşlarına yönelik olarak gerçekleşmiştir. En sık rastlanan saldırgan davranışlar itme, çekme, vurma-engelleme olarak gözlenmiştir. Bu bulgu 5 yaş çocuklarında Tannock (2011) tarafından yapılan çalışmayla oldukça benzerlik göstermektedir.

Fiziksel saldırganlık bazında engelleme davranışlarında oyun sonrasında, oyun öncesine göre anlamlı derecede düşme gözlenmiştir. Bu durum çocukların hareketli oyun ve stafet oyunlarının özünü teşkil eden rekabet davranışları beklentisi nedeniyle saldırgan davranış gösterme eğilimine girebileceklerini düşündürmektedir.

Sözlü saldırganlık davranışlarından yüksek sesle bağırma ve kendi kendine bağırma, oyun sonrasında, oyun öncesine göre anlamlı derecede yükselmiştir. Bu da oyun ortamının aynı zamanda öfke doğuran bir ortam olduğunu göstermektedir. Nitekim benzer şekilde oyun araç-gereç ve malzemelerine yönelik saldırganlık oyun sonrasında, oyun öncesine göre anlamlı derecede artış göstermiştir. Nelson, Gelfand ve Hartmann (1969) bu durumu oyuna bağlı frustrasyon (engellenme hissi) olgusunun, her iki cinsiyette de, ama özellikle erkek çocuklarda saldırganlığı artırmasıyla açıklamışlardır ve çalışmamızla paralel bir sonuç olduğu görülmektedir

Cinsiyet açısından bütün değişkenler içerisinde tek fark, oyun sonrası oyun malzemelerine yönelik saldırganlık erkeklerde daha fazladır. Erkek çocuklar oyun malzemelerine bilinçli olarak basma, parça koparma ve tekmeleme davranışını daha fazla göstermektedir. Bu sonuç Tannock'un (2011) ve çizim testleri açısından değerlendirme yapılan Dağlıŏ̆lu, Deniz ve Kan'ın (2010) bulgularıyla paraleldir. Goodenough Harris çizim testi skorları ile oyun ortamlarında saldırganlık gözlem puanları arasında anlamlı ilişkiye rastlanmamıştır.

Araştırma bulgularından hareketle şu öneriler yapılabilir: Eğitmenler, hareketli oyun ortamlarını saldırganlık davranışlarını en aza indirilebileceği şekilde düzenlemelidir. Oyun ortamlarında erkek öğrenciler ile kız öğrencilerin eşleştirilmesi saldırganlık davranışlarını azaltabilir. Stafet tarzı oyunlar, saldırganlık davranışlarında daha çok takımların kendi oyuncuları arasında görülmektedir. Bunun için, takım oyuncularına bu yönde bir eğitim verilmelidir.

Eğitsel türdeki oyunlar, eğitimde bir araç olarak kullanılacaksa, bu tür oyunların "işbirlikçi” oyunlar olması saldırgan davranışların azalmasına katkı sağlayabilecektir. Oyun araçları oyunlarda, kullanım ömürlerinden daha kısa sürede yıpranmaktadır. Bunun için, oyun materyallerinin ne amaçla oyunlarda kullanılabileceğinin eğitimi çocuklara verilmelidir. Farklı oyun türleri ile ilgili başka araştırmalar yapılarak bunların saldırganlıkla ilişkileri aranabilir. 


\section{Kaynakça}

And, M. (2003). Oyun ve bügü. İstanbul: Yapı Kredi Yayınları.

Baumann, S. (1994). Uygulamalı spor psikolojisi, (Trans: C. İkizler; A.O. Özcan). İstanbul: Alfa Basım Yayın.

Coşkun, A. (2010). Küçük yaşta yoğun spor yapan çocuklarda, bilişsel yapının ve motor gelişimin insan çizim ve motor gelişim testleriyle araştırılması. Unpublished master's thesis, Marmara University, İstanbul.

Dağlıoğlu, H. E., Deniz, Ü., \& Kan, A. (2010). A study on the emotional indicators in 5-6 year-old girls ' and boys' human figure drawings. Procedia Social and Behavioral Sciences, 2, 1503-1510.

Dilekmen, M., Ada, Ş., \& Alver, B. (2011). Ilköğretim II. kademe öğrencilerinin saldırganlık özellikleri. Gaziantep Üniversitesi Sosyal Bilimler Dergisi, 10(2), 927 -944.

Flanders J. L., Simard, M., Paquette , D., Parent S., Vitaro, F., Pihl, O. \& Seguin, J. (2010). Rough-andtumble play and the development of physical aggression and emotion regulation. Journal of Family Violence, 25(4), 357-367.

Huizinga, J. (1949). Homo ludens. London: Routledge \& Kegan Paul Ltd.

ikizler H.C. \& Karagözoğlu, C. (1997). Sporda psikolojik destek. İstanbul: Alfa Basım Yayın.

İnan, M. (2003). Çocuk ve spor, çocuğum nasıl spor yapmalı. İstanbul: Morpa Kültür Yayınları.

İnan, M. (2005). Okul çağında spor, çocuğumla oynuyor, spor yapıyorum. İstanbul: Morpa Kültür Yayınları.

Mavers, D. (2011). Children's drawing and writing. New York: Routlegde.

McCusker, M. \& Van Doren, S. (2007). Aggressive play: contributing factors of parental roles on 3-6 year old boy. College of Saint Elizabeth Journal of the Behavioral Sciences, 1, 27-30.

Nelson, J.D., Gelfand, D.M. \& Hartmann, D.P. (1969). Children's aggreesion following competition and exposure to an aggressive model. Child Development, 40, 1085-1097.

Oktay, A. (1999). Yaşamın sihirli yılları: okul öncesi dönem. İstanbul: Epsilon Yayıncılık.

Onay, C. (2007). Illköğretim okulları için 100 eğitsel oyun. İstanbul: Morpa Kültür Yayınları.

Oğuz, V. (2010). The factors influencing childrens' drawings. Procedia Social and Behavioral Sciences. 2, 3003-3007.

Önder, A. (1999). Yaşayarak öğrenme için eğitici drama. İstanbul: Epsilon Yayınclık.

Pehlivan, H. (2005). Oyun ve öğrenme. Ankara: Anı Yayıncılık.

Sevinç, M. (2004). Erken çocukluk gelişimi ve eğitiminde oyun. İstanbul: Morpa Kültür Yayınları.

Skybo, T., \& Ryan-wenger, N. (2007). Human figure drawings as a measure of children's emotional status. Critical Review for Practice. 22(1), 15-28.

Şahin, H. M. (2002). Beden eğitimi ve spor temel kavramlar. İstanbul: Nobel Yayın Dağıtım.

Şahin, H. M. (2003). Sporda şiddet ve saldırganlık. İstanbul: Nobel Yayın Dağııım.

Tannock, M. (2011). Observing young children's rough-and-tumble play. Australasian Journal of Early Childhood. 36(2), 13-20.

Tiryaki, Ş. (2000). Spor psikolojisi. Ankara: Eylül Yayınları. 
Mehmet INAN, Cengiz KARAGÖZOĞLU ve Özgür şiMŞEK- Pegem Eğitim ve Öğretim Dergisi, 4(1) 2014, 47-58

Uçman, P. (1972). A normative study of the goodenough-harris drawing test on a Turkish sample in cronbach, J., Drent, P.J.D. (Ed). Mental tests and cultural adaptation (pp. 365-375). The Hague: Mouton. 